\title{
A Study of Chip Formation on Turning with Minimum Quantity Lubrication Method (MQL)
}

\author{
Rika Dwi Hidayatul Qoryah1, Agil Widhy Azizi², Mahros Darsin³ \\ 1,3 3 Lecturer in Mechanical Engineering Dept., Faculty of Engineering, \\ University of Jember, Indonesia. \\ Email: mahros.teknik@unej.ac.id \\ ${ }^{2}$ A student in Mechanical Engineering Dept., Faculty of Engineering, \\ University of Jember, Indonesia.
}

Received March 20, 2020; Revised April 5, 2020; Accepted May 12, 2020

\begin{abstract}
The cutting fluid is one of the essential factors in machining to increase machinability. The issuance of ISO 14000 about reducing the use of cutting fluid for its danger for operator and environment has encouraged many researchers to find ways to minimize its use. The Minimum Quantity Lubrication (MQL) is an answer to it. To further reduce the use of cutting fluid, a device that complies with MQL criteria for controlling the spray based on the tool temperature has successfully designed. This paper is discussing the effect of applying this device to the chips formation. The experiments were on turning of AISI 4340 using carbide tools. The Taguchi method L9 used to design the experiments. The variations made on the method of applying the cutting fluid, depth of cut, and cutting fluid composition. The chips formation was calculated based on the value of the degree of serration. Analysis of the S/N ratio, followed by ANOVA, revealed that the cutting fluids application method is the least factor affecting the chips formation. In contrast, the depth of cut influences the chips formation by 75 per cent more. The highest degree of serration achieved when applying the combination of depth of cut of $1.8 \mathrm{~mm}$, the composition of 5:5, and flood method of applying cutting fluid.
\end{abstract}

Keywords: Chip Formation, MQL, degree of serration

\section{INTRODUCTION}

The use of cutting is a substantial factor in machining. The provision of cutting fluid has several functions, including reducing friction between tool and workpiece, reducing heat on the tool to avoid thermal deformation [1], and cleaning the separated chips from the workpiece [2].

Issuance of ISO 14000 has stimulated manufacturing companies to reduce the using of cutting fluid, considering environmental pollution and worker health issue. Some efforts have been in progress, such as using vegetable-based cutting fluids, which is sustainable and safer for the operators 
[3], [4], [5], [6]. Among other attempts, applying minimum quantity lubrication (MQL) is on its way in improving the machined surface as well as reducing the use of cutting fluid [7], [8], [9], [10]. MQL method is a cooling method using coolant or lubricant mixed with compressed air with a speed of $30 \mathrm{~m} / \mathrm{s}$ and liquid between $500 \mathrm{ml} / \mathrm{h}$ [7].

\section{RELATED WORKS}

In MQL, usually, the cutting fluid flow rate is kept continuously. An effort to further reduce cutting fluid during machining is by controlling the cutting fluid spraying process according to the need. In machining, chips formation and friction generate heat. Distribution of heat is $10 \%, 10 \%$, and $80 \%$ to the tool, workpiece, and chips, respectively, in the case of steel machining [11]. Our research group has successfully designed a newly designed MQL spraying system. Spraying of MQL cutting fluid is able to be temperature-controlled by connecting the tool with Arduino controller [12]. Figure 1 is showing how the MQL system works. The sensor position is $3 \mathrm{~mm}$ away from the tooltip. The researchers set the temperature at $70^{\circ} \mathrm{C}$ to enable the cutting fluid spraying when the detected temperature beyond this limit. The spaying will be stopped when the tool cooled down below this limit [13].

The research aims to study chip formation in the presence of this device in the turning process of steel. Chip formation studies are essential as they related to force, quality of machined surface, and tool life [14]-[16]. It also related to the microstructure of the workpiece and the proposed treatment before and after machining [17]-[19]. Chip morphology influenced the machinability to the greater extend [17]. Chip pattern was greatly influenced by machining parameters. In this research, the study of chip formation of AISI 4340 steel will concern on the effect of some parameters variations. The cutting fluid of time-controlled and temperature-controlled MQL will be compared with the flood method.

\section{PROPOSED METHOD}

The study on chips formation would be carried out by observing the chip using naked eye, a normal camera (macro-photo), optic microscope (OM), and scanning electron microscope (SEM). A segmented chips is preferable in machining. The level of segmentation would be calculated by a degree of serration (DOS) following the optical microscope observation. Analysis of the mechanics of chips formation would be carried out base on SEM observation in compare to the existing theory. The Taguchi L9 would be used to design the experiment to study how some machining parameters affect the chips and its formation.

\section{EXPERIMENT AND ANALYSIS Experiment}

Straight turning with conventional machining was performed using a lathe of GUT type C236X1000 with 9 choices of spindle speed between 34 to 
$1400 \mathrm{rpm}$. This machine equipped with cutting fluid gush device, however for this research we made our own design to comply with MQL requirement.

A mini liquid pump completed with an injector and sprayer was installed and connected to the controller. The Arduino controller works either time- or temperature- based. We would use these both options in this research. In the temperature-controlled method, the controller was connected to the sensor which was attached 3-mm from the tip on the flank face of the tool. Figure 1 is showing how the MQL system works. The researchers set the temperature at $70^{\circ} \mathrm{C}$ in the Arduino control system to enable the pump to gush the cutting fluid when the detected temperature beyond this limit. The spraying will be stopped when the tool gets cooled down below $70^{\circ} \mathrm{C}$ [13].

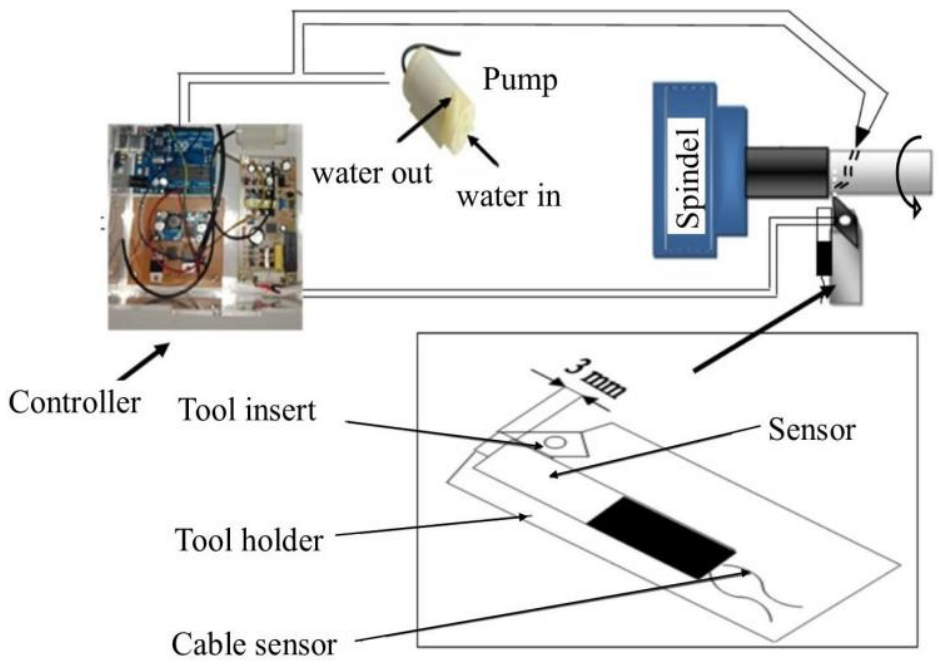

Figure 1. Schematic of temperature control based for MQL in turning process

In the present study, the workpiece is AISI 4340 which has a hardness of $95.9 \mathrm{HB}$ and ultimate tensile strength of $110 \mathrm{~N} / \mathrm{mm}^{2}$. The workpiece is a rod of diameter $35 \mathrm{~mm}$ dan $250 \mathrm{~mm}$ long. Figure 2 shows the schematic of the workpiece. The chemical composition of AISI 4340 is presented in Table 1.
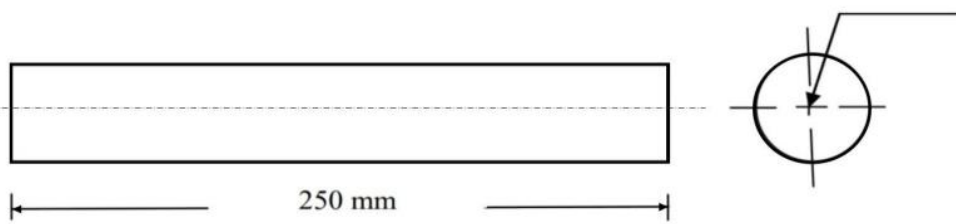

Figure 2. Workpiece dimension 
Table 1. Chemical composition of AISI 4340

\begin{tabular}{|l|l|l|l|l|l|l|l|l|}
\hline Fe & $\mathrm{C}$ & $\mathrm{Cr}$ & $\mathrm{Mn}$ & $\mathrm{Mo}$ & $\mathrm{Ni}$ & $\mathrm{Si}$ & $\mathrm{P}$ & $\mathrm{S}$ \\
\hline Bal & $0.37-0.44$ & $0.7-0.9$ & 0.7 & $0.2-0.3$ & 1.83 & 0.23 & 0.035 & 0.04 \\
\hline
\end{tabular}

The tool used was the carbide insert tool which according to ISO code DCMT11T304. The picture and detail specification of the tool is depicted in Figure 3.

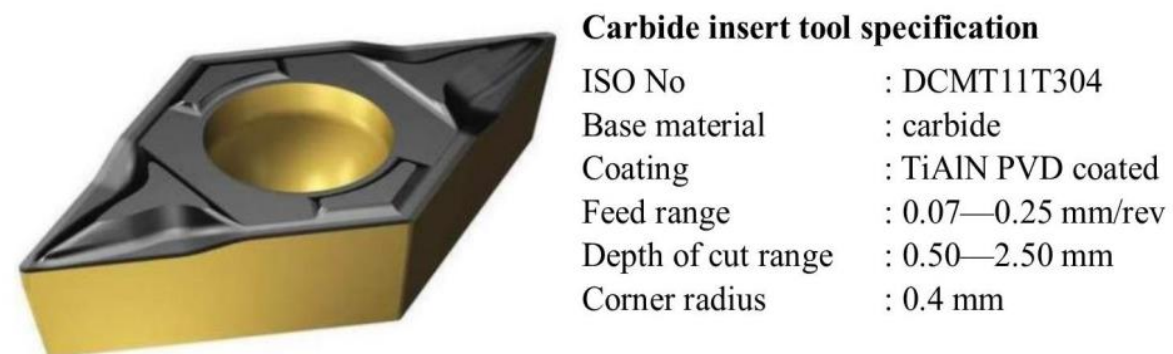

Figure 3. Insert tool specification

To study many several machining parameters together, the Taguchi method was used. Taguchi design proofed that it is a simplified but robust design which requires less number of experiments in comparison to full factorial design [20]. It already used in machining by previous researchers [21], [22], [23]. The Taguchi L9 $\left(3^{3}\right)$ was used in the design of experiments which means 9 combinations of machining parameters. Each combination would be repeated three times. Therefore, we carried out 27 experiments altogether. To ensure the validity of the result, each single experiments using a new tool insert. After calculating the optimum parameter, at the end of Taguchi steps, confirmation experiments would be done to ensure the validation of the calculation [21], [22].

A higher depth of cut was chosen for the sake of easiness of chip observation, however, they were within the working limit of the tool. The cutting fluid made of mixing of cutting oil (known as "dromus" among the machinist) and water. The term of "dromus" will be used for the pure mineral cutting fluid as received. The composition term based on the volume composition at a total of $1300 \mathrm{ml}$ at the time of making the cutting fluid. For example composition of 7:3 means 7 portions of dromus and 3 portions of water. In another word, out of $1300 \mathrm{ml}$ the cutting fluid consist of $900 \mathrm{ml}$ of dromus and $400 \mathrm{ml}$ of water. For the cutting fluid application, three methods were chosen: time-controlled MQL, temperature-controlled MQL and flood. Time-controlled means the cutting fluid was gusted every 7 seconds with 5 seconds spraying time and 2 seconds off. Flood means cutting fluid application without the MQL device. These two types of cutting fluid application would be observed in comparison to the temperature-controlled MQL. The temperature control setting was $70^{\circ} \mathrm{C}$. Three machining parameters and their variation are presented in Table 2. Out of dependent parameters, some other machining 
parameters were kept constant, i.e. spindle speed (n) of $585 \mathrm{rpm}$ and feed rate (f) of $0.108 \mathrm{~mm} / \mathrm{rev}$.

Observation of chip was carried out with naked eye, macro-photo and using an optic microscope and SEM for the selected chips. The chips were collected after each machining and cold mounted in resin. Grinding at several degrees of the roughness of sandpaper, polishing and etching have been carried out carefully prior to microscope observation. Some good looking samples of microscope observation were observed using scanning electron microscopy (SEM).

Table 2. Machining parameters and their level

\begin{tabular}{|c|c|c|c|c|}
\hline \multirow{2}{*}{ Code } & \multirow{2}{*}{ Factor Control } & \multicolumn{3}{|c|}{ Level } \\
\cline { 3 - 5 } & Depth of cut & $1.6 \mathrm{~mm}$ & $\mathbf{2}$ & $\mathbf{3}$ \\
\hline $\mathrm{A}$ & $\mathrm{1}$ & $3: 7$ & $5: 5$ & $2 \mathrm{~mm}$ \\
\hline $\mathrm{B}$ & Composition & $\begin{array}{c}\text { Time-controlled } \\
\text { MQL }\end{array}$ & $\begin{array}{c}\text { Temperature- } \\
\text { controlled MQL }\end{array}$ & Flood \\
\hline C & Method & \multicolumn{3}{|c}{} \\
\hline
\end{tabular}

\section{Analysis}

Observation with naked eyes shows that there is a difference between chips of MQL and flood cutting fluid application. Figure 2 shows the result of chips produced from 3 cooling methods used in this study. Figure 2 (a) and (b) show the chip produced by time-controlled and temperature-controlled MQL respectively. It is evident, that both chips are continuous and snarling or curly, moreover, they are barely unbreakable. With MQL the flow rate of cutting fluid sprayed to the interface between tool and chip are very less. The cutting fluid also works as a drift force to separate chip from the workpiece. When the flow rate of the cutting fluid is very less, there is no sufficient force to initiate a separation. Therefore, the formed chips tend to continuous. This is compounded by the fact that the cutting fluid was intermittently applied.

Flood mode of cutting fluid resulted in different chips form the two above mentioned ones. In the beginning, the chips are spiral, then continuous and snarling type. At the rest of machining session, it was segmented and semisegmented chips as shown in Figure 2 (c). During machining, the heat was generated as a result of shearing in chips formation and friction between chips and tool as well between tool and workpiece. The heat, then, distributed mostly to the chips (about $80 \%$ in case of steel machining). Applying flood cutting fluid as if quenching the chips, therefore it becomes brittle and easily breakdown. The abundant cutting fluid also means high force to drift the chips separate from the workpiece. 


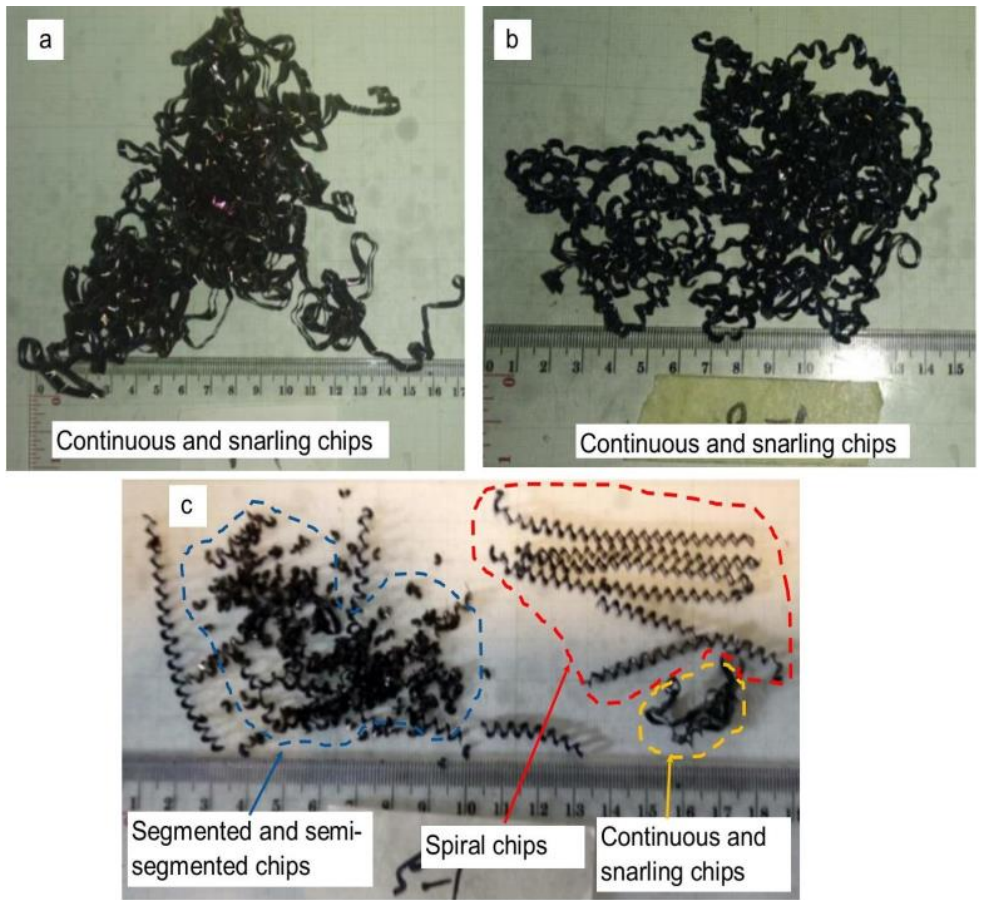

Figure 2. Chips variation as a result of the method of applying cutting fluid (a) Time- controlled MQL, (b) Temperature-controlled MQL, and (c) flood.

Further, observation has been carried out using an optical microscope. Prior to observations, the chips were cold mounted on a resin of $50 \mathrm{~mm}$ in diameter and thickness of about $20 \mathrm{~mm}$ as depicted in Figure 3 (a). The samples, then, ground and polished at several stages; one of which is shown in Figure 3 (b). At the upper side of the chip, there are teeth like profile. Therefore, this chip commonly called as saw tooth chips or serrated chips.
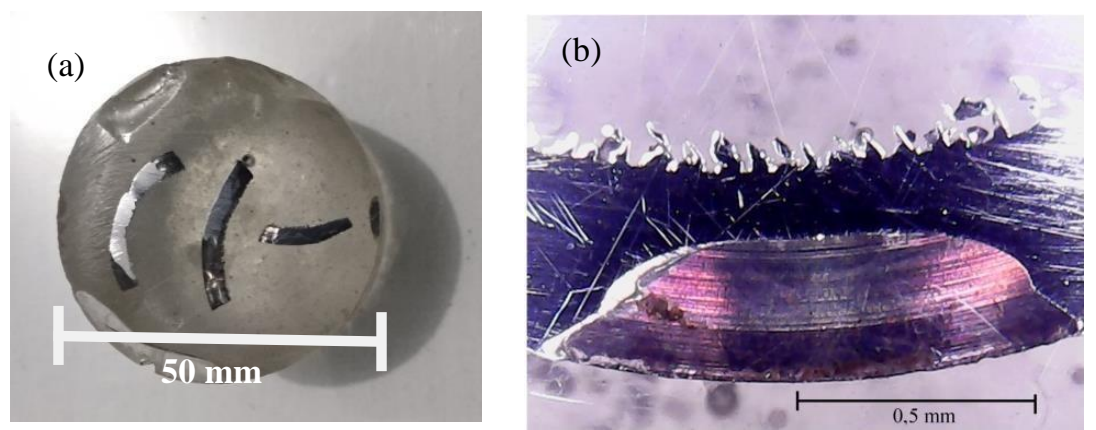

Figure 3. Chips observation using optic microscope: (a) chips are cold mounted followed by grinding and polishing, (b) A sample of microscope photo of chips.

To enable the mathematics calculation of the chips, the degree of serration (DOS) is calculated by comparing the peak (H) to the valley (h) of the tooth. This method has been used by previous researchers [16], [18], [24]. The exaggerated illustration of the saw tooth chips is presented in Figure 4 (a). An 
example of the DOS calculation is shown in Figure 4 (c) following the optic microscopy picture of Figure 4 (b). The DOS data were collected from each combination of machining parameters at least twenty data, to ensure the validity of the data. The average DOS of each experiment is presented in Table 4.
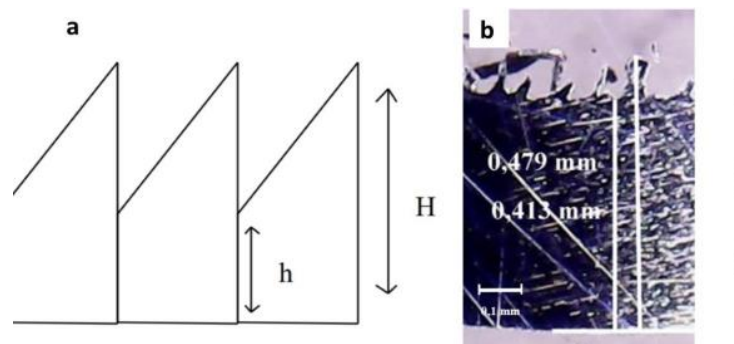

$$
\begin{aligned}
& \text { DOS }=\frac{\mathrm{H}-\mathrm{h}}{\mathrm{H}} \times 100 \% \\
& \text { DOS }=\frac{0,479-0,413}{0,479} \times 100 \% \\
& \text { DOS }=0,138 \%
\end{aligned}
$$

Figure 4. Calculation of degree of serration

The higher the percentage of DOS the easier the chips to brake. In machining the broken chips are preferable. Therefore, the quality criteria of the higher the better would be used in this research. The DOS values obtained are presented in the form of a table according to the L-9 Taguchi design as shown in Table 4 to facilitate further analysis.

Table 4. The degree of serration value

\begin{tabular}{|c|c|c|c|c|c|c|c|}
\hline \multirow{2}{*}{ No } & \multicolumn{3}{|c|}{$\begin{array}{c}\text { Depth of Cut } \\
\text { (mm) }\end{array}$} & \multirow{2}{*}{ Composition } & \multirow{2}{*}{ Method*) } & \multicolumn{3}{c|}{ Degree of serration (\%) } \\
\cline { 5 - 7 } & & & & $\mathbf{1}$ & $\mathbf{2}$ & $\mathbf{3}$ & \\
\hline 1 & 1.6 & $3: 7$ & Time-MQL & 3,669 & 5,538 & 3,647 & 4,285 \\
\hline 2 & 1.6 & $5: 5$ & Temp-MQL & 3,402 & 5,749 & 6,615 & 5,255 \\
\hline 3 & 1.6 & $7: 3$ & Flood & 9,121 & 4,069 & 6,791 & 6,661 \\
\hline 4 & 1.8 & $3: 7$ & Temp-MQL & 5,737 & 6,817 & 5,297 & 5,951 \\
\hline 5 & 1.8 & $5: 5$ & Flood & 5,157 & 11,343 & 5,604 & 7,368 \\
\hline 6 & 1.8 & $7: 3$ & Time-MQL & 6,587 & 6,205 & 5,526 & 6,106 \\
\hline 7 & 2.0 & $3: 7$ & Flood & 2,360 & 3,631 & 3,178 & 3,056 \\
\hline 8 & 2.0 & $5: 5$ & Time-MQL & 3,911 & 3,901 & 3,874 & 3,895 \\
\hline 9 & 2.0 & $7: 3$ & Temp-MQL & 2,825 & 2,918 & 3,936 & 3,226 \\
\hline
\end{tabular}

*) Time-MQL: time-controlled MQL cutting fluid application Temp-MQL: temperature-controlled MQL cutting fluid application 
The data, then, analyzed using Minitab 19 of a free trial version. Figure 5 is showing the mean of means of each machining parameters.

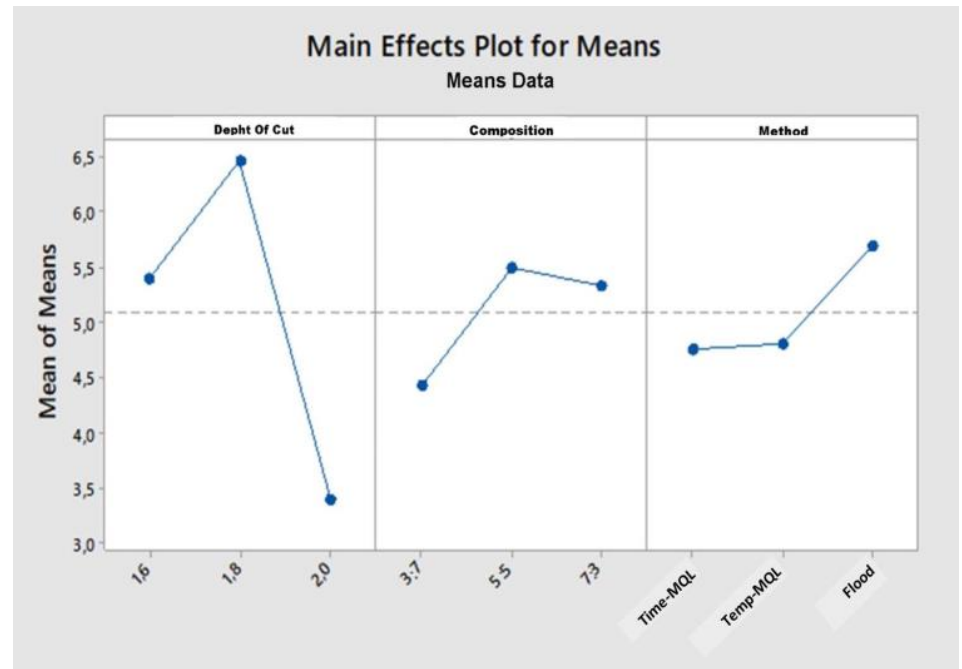

Figure 5. Means plot average value of each machining parameters

Figure 5 revealed that a maximum degree of serration would be achieved by using the value of $1.8 \mathrm{~mm}$; $5: 5$ and flood for machining parameters of the depth of cut, cutting fluid composition and method of applying cutting fluid respectively. The result was summarized in Table 5.

Table 5. Optimum response parameter combination

\begin{tabular}{|c|c|c|c|}
\hline Symbol & Parameter & Level & Value \\
\hline A & Depth of cut & 2 & $1.8 \mathrm{~mm}$ \\
\hline B & Composition & 2 & $5: 5$ \\
\hline C & Method & 3 & Flood \\
\hline
\end{tabular}

To know the significance of all machining parameters, further analysis of ANOVA is explored. With ANOVA the interaction between each factor can also be detected by comparing the value of the mean square to an estimation of experimental errors. ANOVA also showing comparison data at a specific confidence level. The ANOVA analysis of these experiments is presented in Table 6.

The row at Table 6 which is marked 'Error' refers to errors caused by uncontrollable factors, or in the Taguchi model, called 'noise'. The noise comes from: (i) the parameters which are not included in the experiments and (ii) the experimental error. The error in this experiment is $16.770 \%$, which is higher than recommended, that it should be less than $15 \%$. We believe that this error due to other machining parameters which influence the result of the chip but they were excluded from the design of experiments, such as spindle speed (n) and feed rate (f) [25]. However, it is commonly accepted if the error of less than $50 \%$. Beyond this limit, results will not be count as reliable [26]. 
Table 6. Analysis of variation (ANOVA) of means

\begin{tabular}{|c|c|c|c|c|c|}
\hline Source & DF & SS & MS & Fvalue & P \% \\
\hline Depth of cut & 2 & 14,687 & 7,343 & 18,30 & $72,531 \%$ \\
\hline Composition & 2 & 1,999 & 0,999 & 2,49 & $6,249 \%$ \\
\hline Method & 2 & 1,654 & 0,827 & 2,06 & $4,449 \%$ \\
\hline Error & 2 & 0,802 & 0,401 & & $16,770 \%$ \\
\hline Total & 8 & 19,142 & & & \\
\hline
\end{tabular}

It is evident that the depth of cut is outweighed in influencing the value of DOS. On the contrary, the method of applying cutting fluid is the least parameter affecting the DOS value. Figure 6 shows the contribution of each machining parameters in this research to the degree of serration value in per cent.

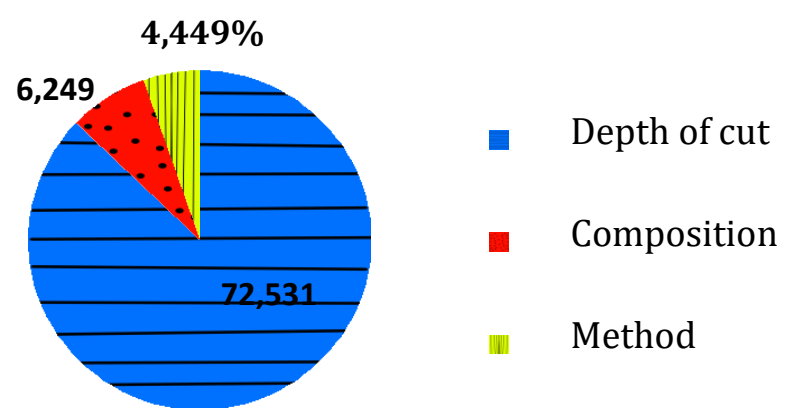

Figure 6. Parameter contribution value

\section{How the machining parameters affecting the DOS value}

Depth of cut is the most influencing factor to the DOS. The bigger depth of cut results in higher DOS value and forms discontinuous chips. While the shallow depth of cut produced thin and smooth chips, resulting in continuous chips. Shallow depth of cut also reduces the cutting zone on chips. Therefore, the structure of chips sheared in the shear zone is narrow, causing low DOS value. Otherwise, higher depth of cut results in thicker chips [27] and of course causing overheat. When the chips are splashed with cutting fluid, a quenching process occurs that causes the chips to become brittle. Higher depth of cut also causes the cutting zone on-chip gets wider, hence the structure sheared onchip also gets wider, resulting in high DOS value. In this research depth of cut of $1.8 \mathrm{~mm}$ resulted in highest DOS value.

The composition control factor is one of the factors that influence this research. From the mean chart in Figure 5 shows that the most optimal composition in producing the highest degree of serration value is $5: 5$. It is because, in the steel machining process, the heat generated is mostly carried by chips so that the chips retain the highest temperature compared to workpiece and tool [8]. High dromus composition affects the cooling process on chips, and the cooling process is faster compared with dry machining as explained by Dhar [28]. Different composition means different viscosity of cutting fluid. Composition of 5:5 has less level of viscosity than that of 3:7. Thin 
liquid is certainly easier to spray through a nozzle. High flow power helps to give a push on chips and forms brittle chips, thus it produces discontinuous chips.

Flood method is a cooling method by spraying cutting fluid towards the interface of tool-workpiece for the entire of machining time. It means that the cooling process occurs continuously during the process of machining. The combination of intense spraying of thin cutting fluid and continuous heavy spraying results in thick chips. Moreover, the sudden cooling process results in brittle chips.

\section{Chips Formation}

The process of chips formation can be analyzed in more detail by scanning electron microscope (SEM) observation to see the transformation of microstructure on chips. Figure 7 shows that the deformation zone on chips is formed due to the shearing of microstructure (shear zone) which causes the formation of a saw-tooth chip or segmented chip. Deformation zone caused by shearing of microstructure can produce catastrophic behaviour on chip which cause a crack and damage to the chip [29]. As explained by Kalpakjian [30] regarding the theory of chip formation, the metal in front of the tool will be compressed due to cutting force (Fc). The first characteristic is elastic and then becomes plastic which causes the formation of a shear zone that will be thrust and released from the workpiece. Illustration of the mechanics of chips formation is presented in Figure 8.

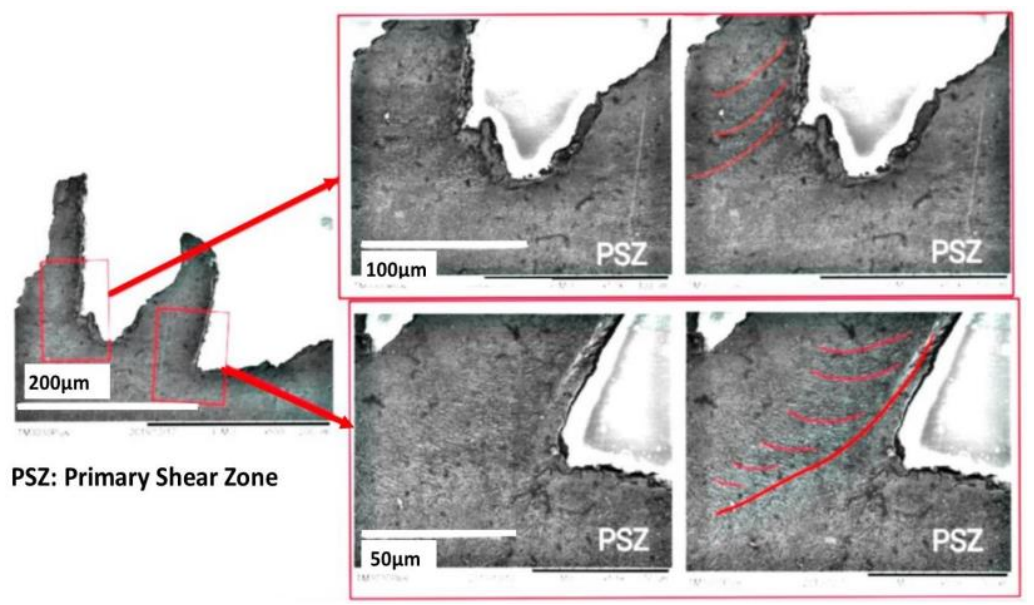

Figure 7. A snapshot of SEM observation result 


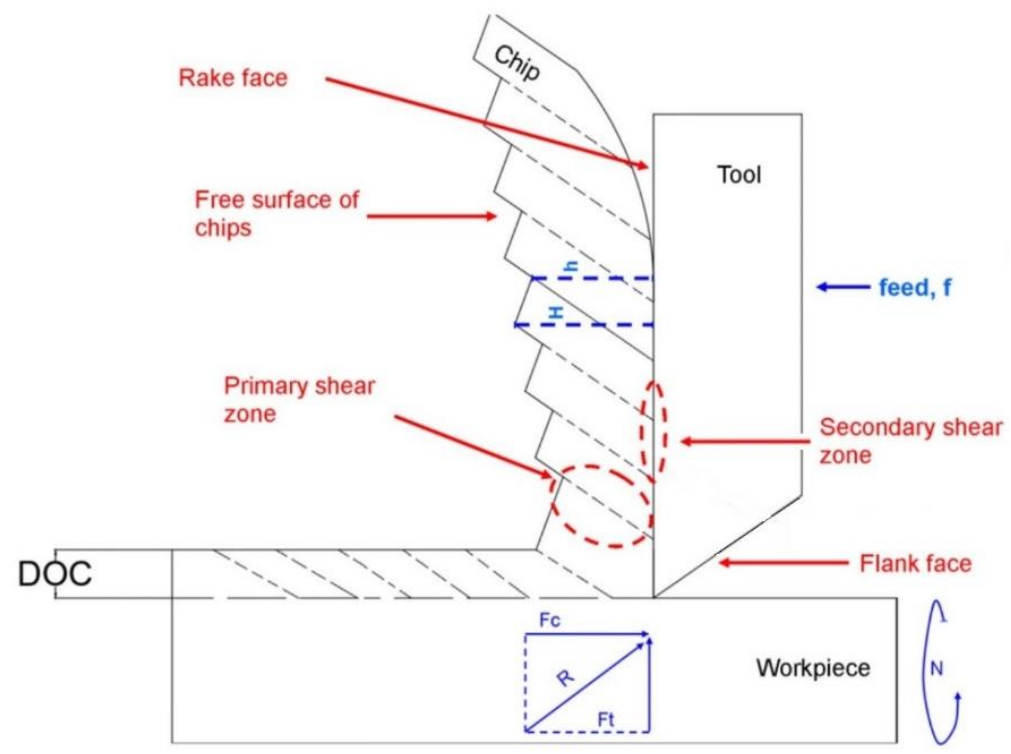

Figure 8. Mechanics of chips formation in turning

As discussed that previously that MQL either time-controlled or temperature-controlled have the least effect to the chips formation. However, the decision of whether we will use the flood type of cutting fluid application will depend on other considerations. Chips formation is only one aspect of machinability point of view. From the aspect of fluid consumption, the use of temperature-controlled MQL resulted in the least consumption [12]. It means machining with temperature-controlled MQL is the most efficient in term of money spent on buying cutting fluid and it is the safest one for the operator. Furthermore, the machinability from machined surface roughness also suggested using temperature-controlled MQL [31]. Therefore machining with temperature-controlled MQL may be still the best alternative, considering that the consumers do concern to parts quality which they received and do not care about the chips as a by-product of machining.

Another result which authors would like to highlight is that applying the Arduino for controlling the MQL cutting fluid is an appreciated achievement in partially machining automation. Automation in machining can be done either partially or thoroughly. Some previous researchers have successful in attempt to gain productivity in non-conventional machining by applying artificial neural network modeling [32].

\section{CONCLUSION}

Based on the result of research conducted on the minimum quantity lubrication method in the process of forming chips, it can be concluded:

1. The cooling method, including the MQL, did not have a significant effect on the chips formation. Out of three cutting method application, the flood method revealed as the best method to create discontinuous chips. In contrast, the depth of cut is the most dominant factor affecting the chips 
formation.

2. The optimum parameter combination which would result in the highest degree of serration is at the depth of cut of $1.8 \mathrm{~mm}$, balance composition between mineral oil (dromus) and water and flood method of cutting fluid application.

3. The final recommendation is machining with temperature-controlled MQL considering other perspectives of machinability.

\section{ACKOWLEDGEMENTS}

We would like to thank the Department of Mechanical Engineering University of Jember for facilitating this research. We would like to acknowledge our colleagues in the research group of the MQL: Maulana Muhammad Firdaus, Dicky Aprilian Nugraha, Gerry Gardika Surya Dinata, and Allen Luviandy who have hard worked together in completing this research.

\section{REFERENCES}

[1] S. K. Thangarasu, S. Shankar, A. Tony Thomas, and G. Sridhar, Prediction of Cutting Force in Turning Process-an Experimental Approach, IOP Conf. Ser. Mater. Sci. Eng., vol. 310, no. 1, 2018.

[2] N. Boubekri and V. Shaikh, Minimum Quantity Lubrication (MQL) in Machining: Benefits and Drawbacks, J. Ind. Intell. Inf., vol. 3, no. 3, pp. 205-209, 2015.

[3] M. Li, T. Yu, L. Yang, H. Li, R. Zhang, and W. Wang, Parameter optimization during minimum quantity lubrication milling of TC4 alloy with graphene-dispersed vegetable-oil-based cutting fluid, $J$. Clean. Prod., vol. 209, pp. 1508-1522, 2019.

[4] S. Albert, I. Ahmed, and Y. Nukman, A critical assessment of lubrication techniques in machining processes : a case for minimum quantity lubrication using vegetable oil-based lubricant, vol. 41, pp. 210-221, 2013.

[5] M. Nizamuddin, S. M. Agrawal, and N. Patil, The Effect of Karanja based Soluble Cutting Fluid on Chips Formation in Orthogonal Cutting Process of AISI 1045 Steel, Procedia Manuf., vol. 20, pp. 12-17, 2018.

[6] W. L. R. Fernando, N. Sarmilan, K. C. Wickramasinghe, H. M. C. M. Herath, and G. I. P. Perera, Materials Today: Proceedings Experimental investigation of Minimum Quantity Lubrication ( MQL ) of coconut oil-based Metal Working Fluid, no. Xxxx, 2019.

[7] S. K. Ali, S.M., Dhar, N.R., Dey, Effect of Minimum Quantity Lubrication (Mql) on Cutting Performance in Turning Medium Carbon Steel By Uncoated Carbide Insert At Different Speed-Feed Combinations, $A d v$. Prod. Eng. Manag., vol. 6, no. 3, pp. 185-196, 2011.

[8] S. B. Kedare, D. R. Borse, and P. T. Shahane, Effect of Minimum Quantity Lubrication (MQL) on Surface Roughness of Mild Steel of 15HRC on Universal Milling Machine, Procedia Mater. Sci., vol. 6, no. Icmpc, pp. 
150-153, 2014.

[9] E. A. Raheem and H. Dorairaju, Evaluation of mist flow characteristic and performance in minimum quantity lubrication (MQL) machining, Measurement, vol. 123, no. July, pp. 213-225, 2018.

[10] S. Ekinovic, H. Prcanovic, and E. Begovic, Investigation of influence of MQL machining parameters on cutting forces during MQL turning of carbon steel St52-3, Procedia Eng., vol. 132, pp. 608-614, 2015.

[11] S. Pervaiz, S. Pervaiz, A. Rashid, I. Deiab, and M. Nicolescu, Influence of Tool Materials on Machinability of Titanium- and Nickel-Based Alloys : A Review Influence of Tool Materials on Machinability of Titanium- and Nickel-Based Alloys : A Review, Mater. Manuf. Process., vol. 29, no. April 2014, pp. 37-41, 2014.

[12] G. G. S. Dinata, A. Z. Muttaqin, and M. Darsin, Rancang bangun dan uji performa sistem kendali pemberian fluida permesinan MQL berbasis arduino, Rekayasa Mesin, vol. 11, no. 1, pp. 97-104, 2020.

[13] G. G. S. Dinata, Perancangan Sistem Kendali Pemberian Fluida Permesinan Berbasis MQL pada Mesin Bubut dan Analisis Performanya, Universitas Jember, 2019.

[14] M. Darsin, "Drillability Of Titanium 6246 From Chips Formation Perspective."

[15] M. Yasir, T. L. Ginta, B. Ariwahjoedi, M. Danish, and A. U. Alkali, Evaluation of chips formation of AISI 316L SS using precision endmilling, APRN J. Eng. Appl. Sciences, vol. 11, no. 22, pp. 12903-12907, 2016.

[16] M. Darsin, D. Dwilaksana, T. Pasang, and Z. Chen, Study on effect of heat treatment on chips formation and forces in drilling titanium alloy 6Al-2Sn-4Zr-6Mo, 2019.

[17] M. Darsin, T. Pasang, and Z. Chen, A Study on Serrated Chips Formation in Drilling Ti-6246, in 28th New Zealand Conference on Microscopy, 2017.

[18] C. Duan and M. Wang, Microstructure and mechanism of adiabatic shear fracture during serrated chip formation of hard machining, $J$. Adv. Mech. Des. Syst. Manuf., vol. 8, no. 6, pp. 1-12, 2014.

[19] M. Darsin, T. Pasang, and Z. Chen, Drillability of Titanium 6246 Alloy, in Processing and Fabrication of Advanced Materials XXV, 2017, pp. 856861.

[20] M. N. Islam and A. Pramanik, Comparison of Design of Experiments via Traditional and Taguchi Method, J. Adv. Manuf. Syst., vol. 15, no. 3, pp. 151-160, 2016.

[21] N. Khanna and J. P. Davim, Design-of-experiments application in machining titanium alloys for aerospace structural components, vol. 61, pp. 280-290, 2015.

[22] N. Khanna, Design of Experiments in Production Engineering, no. January. 2016.

[23] M. Darsin, T. Pasang, and Z. Chen, Forces Perspective of Drillability of 
Titanium Alloy 6Al-2Sn-4Zr-6Mo, J. Energy, Mech. Mater. Manuf. Eng., vol. 3, no. 1, p. 23, Jun. 2018.

[24] J. Zang, J. Zhao, A. Li, and J. Pang, Serrated chip formation mechanism analysis for machining of titanium alloy Ti-6Al-4V based on thermal property, Int. J. Adv. Manuf. Technol., vol. 98, no. 1-4, pp. 119-127, 2018.

[25] M. H. Ali, B. A. Khidhir, B. Mohamed, and A. A. Oshkour, Investigation on Chip Formation during Machining Using Finite Element Investigation on Chip Formation during Machining Using Finite Element Modeling, no. April 2012.

[26] Clove oil nanoemulsion as an effective antibacterial agent : Taguchi optimization method Clove oil nanoemulsion as an effective antibacterial agent: Taguchi optimization method, no. November 2015, 2016.

[27] M. C. Shaw, Mechanics of Saw-Tooth Chip Formation in Metal Cutting H I-, vol. 2, no. d, 2016.

[28] N. R. Dhar, M. Kamruzzaman, and M. Ahmed, Effect of minimum quantity lubrication (MQL) on tool wear and surface roughness in turning AISI-4340 steel, vol. 172, pp. 299-304, 2006.

[29] T. Mabrouki et al., Comptes Rendus Mecanique Some insights on the modelling of chip formation and its morphology during metal cutting operations Hybrid Dynamic Cutting model, Comptes Rendus Mec., vol. 344, no. 4-5, pp. 335-354, 2016.

[30] S. Kalpakjian and S. Schmid, Manufacturing Engineering and Technology, 4th ed. Pearson, 2001.

[31] D. A. Nugraha, R. D. H. Qoryah, and M. Darsin, Pengaruh Metode Minimum Quantity Lubrication ( MQL ) terhadap Nilai Kekasaran Permukaan (Effect of Minimum Quantity Lubrication (MQL) Method on Surface Roughness), Rekayasa J. Sci. Technol., vol. 13, no. 2, pp. 125129, 2020.

[32] M. A. Mohd Zakaria, R. I. Raja Abdullah, M. S. Kasim, and M. H. Ibrahim, Enhancing the Productivity of Wire Electrical Discharge Machining Toward Sustainable Production by using Artificial Neural Network Modelling, Emit. Int. J. Eng. Technol., vol. 7, no. 1, pp. 261-274, 2019. 